\title{
Strengthen and Improvement of Specialty Characteristic under the Background of Engineering Education Accreditation
}

\author{
De-chun SUN ${ }^{*}$ Zu-jun LIU and Yong-jun SUN \\ Xidian University, Xi'an, Shaanxi, China \\ ${ }^{*}$ Corresponding author
}

Keywords: Higher education, Engineering education accreditation, Specialty characteristic.

\begin{abstract}
Engineering education accreditation provides omnibearing quality control standards and mechanisms for the university engineering specialties, and hence has been widely applied. The engineering education accreditation in China adopts comprehensive, reasonable and operable graduate attributes that are substantially equivalent to the graduate attributes proposed by the Washington Accord. The problem comes from the fact that the same specialties of different universities use almost the same statements for the graduate attributes, which, although the effectiveness of quality control, will diminish the specialty characteristics. Aiming at this problem, four measures are proposed in this paper to strengthen the specialty characteristics. These measures relate to the training target setting, the statements for graduate attributes, the construction of curricula system and unequal weights setting for different graduate attributes.
\end{abstract}

\section{工程教育认证背景下专业特色的强化和提升}

\author{
孙德春”, 刘祖军, 孙永军
}

西安电子科技大学, 西安, 中国

关键词：高等教育; 工程教育认证；专业特色

摘要：工程教育专业认证为高等学校工科专业提供了全方位的质量控制标准和机制, 因此在 我国得到了大力推广。我国的工程教育认证采用与华盛顿协议所提出的毕业要求实质等效的 毕业要求，其具有全面、科学、可操作等优良性质。但在实践中，不同高校的相同专业往往 采用完全相同或者几乎完全相同的毕业要求表述。这样的操作方式虽然能有效地依照标准对 毕业生质量进行控制, 但却难以体现专业特色。针对该问题, 本文提出了四个方面的举措, 从培养目标的设定、毕业要求的表述、课程体系的构建及差异化毕业要求权重设定等方面入 手，为专业特色的体现和提升提供了思路。

\section{1. 引言}

随着我国高等教育事业的飞速发展和高等教育水平的不断提升，工程教育质量控制已经 成为保证高等教育健康发展的一个重要课题。而工程教育专业认证就提供了全方位多角度的 高等教育质量控制机制, 因此成为了国际通行的工程教育质量保证制度, 同时也为工程教育 国际互认和工程师资格国际互认提供了制度基础[1]。因此, 我国也大力推进高等学校工科专 业的专业认证工作 ${ }^{[2]}$ 。

2016年6月召开的国际工程联盟大会全会全票通过了中国的转正申请, 中国成为第18个

《华盛顿协议》 ${ }^{[3]}$ 正式成员。这对我国的工程教育认证具有划时代的意义，其标志着我国的 工程教育培养质量和相关的保障制度得到了国际工程教育界的认可, 通过我国工程教育认证 
的专业毕业生的学位将被所有《华盛顿协议》缔约国承认。同时也标志着我国工程教育已实 现国际化，可促进工程类产业的国际化发展。

我国所采纳的工程教育认证标准由通用标准和专业补充标准两部分构成 ${ }^{[4]}$ 。通用标准规 定了专业在学生、培养目标、毕业要求、持续改进、课程体系、师资队伍和支持条件 7 个方面 的要求; 专业补充标准规定相应专业领域在上述一个或多个方面的特殊要求和补充。认证标 准各项指标的逻辑关系为: 以学生为中心, 以培养目标和毕业要求为导向, 通过足够的师资 队伍和完备的支持条件保证各类课程教学的有效实施, 并通过完善的内外部质量控制机制进 行持续改进, 最终保证学生培养质量满足要求。

作为《华盛顿协议》的成员国, 参照《华盛顿协议》提出的毕业设计标准, 我国的工程 教育认证体系对毕业生提出了十二个方面的要求。为了实现对这十二条毕业要求的有效支撑, 目前各专业一般采用的方法是：首先对十二条毕业要求进行分解, 形成若干个指标点, 然后 对各个指标点设置对应的支撑课程, 从而在培养过程中实现对各指标点的支撑, 最终实现对 对应毕业要求的支撑。在实际操作中, 不同高校的相同专业往往采用完全相同或者几乎完全 相同的毕业要求表述, 这样的方式虽然能有效地依照标准对毕业生质量进行控制, 但是却难 以体现不同高校的专业特色。因此, 本文探讨在工程认证的大背景下如何有效地实现专业特 色的体现和提升。

\section{2. 专业特色体现和提升措施}

本文考虑采取四个方面的措施对专业特色进行体现和提升。首先, 在专业的培养目标方 面, 要结合学校定位进行适当的定位; 其次, 在毕业要求表述方面, 应基于专业培养目标精 准定义本专业复杂工程问题, 继而基于该复杂工程问题进行合理的毕业要求表述; 再次, 在 课程体系方面, 可以根据专业特点突出特色课程和特色培养环节; 最后, 在衡量毕业要求对 培养目标的支撑情况时, 可以对十二条毕业要求设置不同的权重, 从而体现专业特色。

\section{1 差异化培养目标的设定}

培养目标是衡量专业定位和毕业生培养水平的重要指标。虽然在毕业要求的表述中并不 直接涉及培养目标, 但是由于所设定的培养目标要以专业提出的毕业要求作为支撑, 因此实 际上培养目标间接决定了毕业要求, 继而专业特色的体现和提升也可以通过设定适当的培养 目标来实现。

培养目标需要符合学校定位, 并能反映学生毕业后5年左右在社会与专业领域预期取得的 成就, 因此该目标的设定与学校办学水平和定位密切相关。专业培养目标的设定, 应该契合 学校定位。当然培养目标是反映学生毕业5年左右的社会与专业领域成就, 而学校定位则并不 局限于该时间限制, 因此一般来说学校定位中的人才培养目标高于专业所描述的人才培养目 标。这样专业在制定培养目标时, 应该基于本专业的培养水平, 制定贴近学校人才培养目标 的、同时又反映专业实际培养质量的培养目标。例如某高校定位中的人才培养目标为“培 养......的行业骨干和引领者” , 其中 “行业骨干”是较为容易实现的培养目标, 而“引领者”这一 目标更难达到。在这样的学校人才培养目标前提下，学校的不同专业就可以依据自身水平制 定合适的人才培养目标。对于学校的优势专业, 可以以“引领者”为参照制定专业的培养目标, 对于非优势专业, 可以以“行业骨干”为参照制定专业的培养目标。通过与学校定位的结合, 不同高校的相同专业也将具有差异化的培养目标, 从而在根本上决定了对差异化培养目标进 行支撑的毕业要求也将呈现差异化特征。

\section{2 毕业要求的个性化表述}

如前文所述, 专业在对毕业要求进行表述的时候, 往往直接采用工程教育认证体系提出 的十二条毕业要求, 因此容易导致毕业要求表述的高度重合, 因此需要探索解决这一问题的 方法。 
由于我国的工程教育认证体系符合《华盛顿协议》的要求，而《华盛顿协议》为了区别 于 “悉尼协议”(相当于专科或高职层次的教育互认体系)和“都柏林协议”(相当于中专层次的教 育互认协议), 特别强调了工科类本科专业对 “解决复杂工程问题”的要求。因此可以从“复杂 工程问题”入手, 实现个性化的毕业要求表述。具体做法是: 专业首先精准地定义本专业所要 解决的 “复杂工程问题”, 然后围绕这一“复杂工程问题”对十二条毕业要求进行符合专业实际 的、个性化的表述。由于 “复杂工程问题” 具有非常丰富的内涵, 因此不同高校的具有不同办 学水平的专业完全可以对自身所要解决的 “复杂工程问题”进行符合专业实际的定义，在此基 础上, 将本专业“复杂工程问题” 的内涵融入到毕业要求的诸项表述中, 突出各项能力的指向 是解决本专业的“复杂工程问题”, 而非一般性问题。例如, 在结合了专业的“复杂工程问题” 后, 某专业对于毕业要求中“工程知识”的个性化表述为“能将数学、自然科学、工程基础和专 业知识用于解决 $\times \times$ 工程中的分析诊断、研究设计、规划管理、集成实现、性能评估、优化升 级等问题”。比起原始的“能将数学、自然科学、工程基础和专业知识用于解决复杂工程问题” 就更加具体，也更能体现专业的特色。

\section{3 课程体系的考量}

虽然不如毕业要求的表述那样能直观地反映专业特色, 但实际上课程体系是最能体现专 业特色的部分。对于这个部分, 各专业具有最大的发挥空间, 可以将本专业的特色课程、优 势课程合理地纳入课程体系中。专业需要做的, 就是将十二条毕业要求分解成更为具体的若 干个指标点, 然后针对各个指标点, 指定相应的课程进行支撑。

同时对于部分工科专业, 工程教育认证的补充标准也为让专业能够依据自身特色构建课 程体系。例如电子信息与电气工程类专业的补充标准中, 关于通信工程专业的课程体系中, 要求在数字信号处理、通信技术基础、通信电路与系统、信号与信息处理、信息理论基础、 信息网络、信息获取与检测技术等 7 个知识领域, 至少包括 4 个知识领域的核心内容。这就为 不同学校的通信工程专业设置个性化的课程体系创造了条件, 专业可以将最能反映本专业特 色和实力的知识领域的相关课程纳入专业的课程体系中, 体现并提升专业特色。

\section{4 不同毕业要求的差异化权重考量}

工程教育认证要求专业所提的十二条毕业要求能够支撑专业的培养目标, 同时要求课程 体系能够完全支撑这十二条毕业要求。特别地, 对于毕业要求来说, 只要能够证明其“达成”, 则都能够满足工程教育认证的要求。

实际上, 为了提升专业特色, 专业可以在保证所有毕业要求“达成”的前提下，突出专业 对若干个毕业要求的更加“优质”的“达成”。这种更加“优质”的“达成”，是在满足基本要求的基 础之上的、能够让专业的毕业生打上专业烙印的一种有效手段, 实际上就是对专业特色的体 现和提升。这种方法实际上是在培养体系中, 让不同的毕业要求具有不同的权重, 从而用差 异化的权重来体现专业特色。例如作者所在的专业通过举覆盖所有学生的课外学术科技作品 竞赛, 着重加强了对学生在“设计/开发解决方案”和“研究”这两个毕业要求的培养。这样在保 证所有十二条毕业要求都“达成”的前提下, 以这两个毕业要求的更高权重体现和提升了专业 特色。

\section{3. 结束语}

本文探讨了专业认证背景下的专业特色体现和提升问题，提出了四个方面的举措，从培 养目标的设定、毕业要求的表述、课程体系的构建及差异化毕业要求权重设定等方面入手, 为专业特色的体现和提升提供了思路。这四方面的举措是：培养目标配合学校定位, 实现差 异化设定; 基于专业定义的复杂工程问题进行专业毕业要求的个性化表述; 以特色课程和特 色培养环节为课程体系增添亮点; 在满足毕业要求的前提下突出若干毕业要求, 强化专业特 
色。这些举措涵盖了从培养目标到课程体系的多个方面, 且具有较强的可操作性, 综合使用 举措将能有效体现和提升专业特色。

\section{致谢}

本文为西安电子科技大学校级教育改革研究项目《在专业认证标准下学校专业特色的体 现与提升》的阶段性成果之一。

\section{References}

[1] Bordia surek, Problems of Accreditation and Quality Assurance of Engineering Education in Developing Countries, J. European Journal of Engineering Education. 26(2) 187-193, 2001.

[2] Information on http://www.ceeaa.org.cn/

[3] Information on http://www.ieagreements.org/

[4] China Engineering Education Accreditation Association Secretariat, Operation Guidelines for Engineering Education Accreditation, 2015 Edition, Beijing, 2015. 